\author{
УДК 332.1(07) \\ РЕШЕНИЕ ПРОБЛЕМ ГРАДООБРАЗУЮЩИХ ПРЕДПРИЯТИЙ КАК ПЕРСПЕКТИВА \\ РАЗВИТИЯ МОНОГОРОДОВ \\ татьяна А. Смирнова ${ }^{1, @}$ \\ ${ }^{1}$ Сибирский федеральный университет, 660041, Россия, г. Красноярск, пр. Свободный, 79 \\ @smirtatan@yandex.ru
}

Поступила в редакцию 31.01.2018. Принята к печати 17.04.2018.

Ключевые слова: социально-экономическое развитие, сырьевое обеспечение, глиноземное производство, моногорода, комплексная переработка, промышленная политика, градообразующее предприятие.
Аннотация: Предприятия отраслей специализации существенным образом определяют эффективность функционирования отдельных территорий, тем самым оказывая комплексное влияние на социально-экономическое положение моногородов и в целом их территориальное развитие. В этой связи проблемы отдельных производств должны рассматриваться как общие проблемы развития всей территориальной системы, а их решение будет способствовать более эффективному развитию территорий. В результате проведенного исследования выявлены основные проблемы функционирования одного из основных звеньев алюминиевой промышленности - глиноземного производства. В результате проведения полного цикла расчетов по взаимосвязанной системе эконометрических моделей глиноземного производства автором была проведена оценка возможных вариантов сырьевого обеспечения, выявлены актуальные направления решения проблем градообразующих предприятий алюминиевого комплекса. Для решения одной из самых острых проблем предложен инструментарий, позволяющий осуществить выбор оптимального варианта сырьевого обеспечения, что обеспечит стабильную работу предприятия и позволит достичь устойчивого развития территории. Предложены мероприятия промышленной политики, позволяющие решить проблемы не только отдельного предприятия и отрасли, но и создающие условия для стабильного развития моногородов.

Для цитирования: Смирнова Т. А. Решение проблем градообразующих предприятий как перспектива развития моногородов // Вестник Кемеровского государственного университета. Серия: Политические, социологические и экономические науки. 2018. № 3. C. 162-167. DOI:10.21603/2500-3372-2018-3-162-167.

Социально-экономическое развитие любого государства строится на стабильном функционировании и совершенствовании его народнохозяйственного комплекса. При этом особого внимания заслуживают те сферы экономики, которые обеспечивают основу и создают перспективы для экономического развития территорий. Они обеспечивают мультипликационные эффекты, обеспечивая развитие, прежде всего, тех территорий, на которых осуществляют свою деятельность по созданию продукта. Значение показателей эффектов будет зависеть от существующего на территории «производственного каркаса» экономической и производственной деятельности, и если в основе его функционирования находится одно крупное предприятие, то именно оно и будет создавать импульсы для развития территории, определяя ее дальнейшие перспективы. Прежде всего, речь идет о моногородах. Моногород представляет собой особый тип социально-экономических образований, не теряющий своей значимости в современных динамических процессах развития экономики Российской Федерации [1]. В этом случае социально-экономическое состояние города во многом определяется функционированием и развитием самого предприятия. Устойчивое развитие моногородов связано со стабильной работой градообразующего предприятия или группы предприятий одной отраслевой принадлежности [2]. Градообразующее предприятие в системе экономических отношений стоит обособленно в силу того, что его интересы могут превалировать над интересами остальных хозяйствующих субъектов, так как оно играет основную системообразующую роль [3]. Сокращение производства, особенно крупного, приводит к адекватному снижению спроса на используемые ресурсы со стороны этого предприятия, в том числе и на рабочую силу, что вызывает рост безработицы в рамках территории, происходит сокращение налогооблагаемой базы и т. д. Таким образом, «неудачи» отдельного предприятия превращаются в проблемы города, региона и государства в целом. Напротив, в случае улучшения производственных и экономических результатов деятельности градообразующего предприятия наблюдается рост занятости, повышение заработной платы и доходов населения, увеличение предпринимательской активности и т. п. во всей социально-экономической системе. Полученный в этих условиях результат может быть выражен в количественном росте эффективности всей отраслевой структуры реального сектора экономики, в снижении экономической неопределенности и рисков, а также в стабилизации ин- 
вестиционной основы модернизации и устойчивости контрактных отношений на входе и выходе их производственных систем [4].

Производственная структура развития большинства моногородов в современной России мало отличается от той, которая сложилась во времена плановой экономики. На сегодняшний день она характеризуется наличием значительных проблем, попытки решения которых представлены в различных исследованиях ученых. Для таких территорий характерная особая острота проблем: демографическая, социально-экономическая, экологическая и т. д. [5]. На сегодняшний день разработаны стратегии экономического и социального развития, в которых представлен анализ положения и перспективы развития территории, выделены конкурентные преимущества территориальных систем, освещены угрозы и возможности, направления и перспективы территориального развития, а также предложены меры по улучшению параметров экономического и социального развития. При этом затрагиваются лишь отдельные стороны функционирования социально-экономической системы, без учета влияния деятельности градообразующих предприятий на ее дальнейшее развитие. Между тем перспективы развития отдельных территорий в нашей стране зависят от деятельности конкретных производств и отраслей, которые в свою очередь «обрастая» обслуживающими производствами, объектами социальной и производственной инфраструктуры, образуют территориальную систему. Таким образом, стабильное функционирование градообразующих предприятий определяет устойчивое развитие территории.

При формировании и корректировке территориально-хозяйственной структуры моногорода с учетом тех изменений и сдвигов, которые происходят в экономике, как никогда становится актуальным всесторонний подход к оценке влияния функционирования градообразующих предприятий на всю социально-экономическую систему. Прежде всего, требуется обозначить вектор дальнейшего развития градообразующих предприятий моногородов для выведения их из депрессивных экономических зон с последующим их превращением в локомотивы российской экономики [6].

Сложность системы взаимосвязей и взаимодействий обусловливает требования к обоснованию мероприятий в области социальной и экономической политики на региональном уровне, при этом оценка только прямых эффектов от реализации тех или иных управленческих решений зачастую является недостаточной. При формировании новой региональной политики необходима комплексная оценка влияния функционирования отраслей специализации на экономическое и социальное развитие территории, что позволит в дальнейшем предлагать эффективные мероприятия промышленной политики с учетом их всестороннего влияния на развитие общества.

Существующие программы экономического развития территорий дают описание общего развития производственного комплекса, не уточняя направления стратегического и тактического развития отраслей специализации национальной экономики, при этом именно эти отрасли являются фундаментом развития для целого ряда городов и регионов России, а их успешная работа создает импульсы для стабильного функционирования экономической и социальной сфер. Связь между жизненным циклом отрасли и региональным ростом заключается в том, что последний зависит от того, какие отрасли преобладают в том или ином регионе [7].

Оценивая влияние результатов функционирования градообразующего предприятия на весь комплекс функционирующих сфер (предприятий специализации, обслуживающих и вспомогательных производств) моногорода и его социально-экономическое развитие, можно выстроить сбалансированную региональную политику, учитывающую интересы бизнеса, населения и общества в целом. Такая оценка необходима, прежде всего, при определении приоритетных направлений государственной поддержки отдельных предприятий и отраслей в условиях бюджетных ограничений. Все это позволит достичь более высоких показателей социально-экономического развития монофункциональных территорий от проведения конкретных мероприятий.

Основным сектором экономики России является материальное производство, в котором весомая роль отводится металлургическому производству, в том числе и алюминиевой промышленности. Большинство предприятий алюминиевого комплекса являются градообразующими и системообразующими. С одной стороны, это означает высокую значимость производимой продукции и оказываемых услуг для жизнеобеспечения отдельных территорий и отраслей в масштабах отдельных регионов и страны в целом, с другой стороны, градообразующие предприятия создают основу для развития производственной и социальной инфраструктур моногородов.

В настоящее время на российскую алюминиевую промышленность существенное воздействие оказывает ряд факторов, непосредственно влияющих на перспективы ее дальнейшего развития. Среди них отсутствие месторождений высококачественного алюминийсодержащего сырья, нахождение большинства предприятий на значительном удалении от границ Российской Федерации и рост железнодорожных тарифов, обострение экологических проблем. Данные факторы, по мнению автора, определяют проблемы функционирования отрасли и связаны с неэффективными формами хозяйствования, отсутствием комплексной переработки сырья и стабильной сырьевой базы, растущей угрозой экологической составляющей этих производств, ослаблением роли государственной поддержки.

Наибольшие объемы производимой в стране алюминиевой продукции приходятся на Сибирь. При этом единственное предприятие, которое производит и поставляет глинозем Красноярскому алюминиевому заводу - Ачинский глиноземный комбинат (АГК). Максимальное количество полуфабриката, которое АГК поставляет для дальнейшей переработки, составляет около 1 млн тонн глинозема в год, тогда как совокупная потребность алюминиевых заводов Сибири превыша- 
ет 5 млн тонн. Ситуацию усугубляет и истощение действующего месторождения алюминийсодержащего сырья (нефелиновой руды), которое по оценкам экспертов может эксплуатироваться до 2020 г.

Существенным недостатком предприятий алюминиевого комплекса является образование значительного количества экологически опасных отходов. Сокращение направлений и объемов комплексной переработки сырья за годы рыночных преобразований привели к ухудшению экологической ситуации и все возрастающим с каждым годом объемам отходов, что создает серьезные препятствия для дальнейшей деятельности предприятий. Кроме того, образование таких отходов приводит к изъятию из землепользования значительных земельных участков, необходимости разработки и реализации проектно-сметной документации для строительства шламовых полей и внушительным эксплуатационным расходам по их содержанию, растущим расходам на текущие платежи за загрязнение окружающей среды.

При комплексной переработке нефелинового сырья в наибольшем количестве получают цемент (8 тонн цемента при производстве 1 тонны глинозема). Возможность получения соды из нефелинового сырья заменяет ее производство из хлористого натрия по аммиачному методу, который связан с внушительным экологическим ущербом. В то время как получение соды из нефелинового сырья практически полностью безотходно. Получение другого продукта - поташа - является эффективным только при применении нефелинового сырья. Существенное расширение масштабов использования поташа сдерживается недостатком этого продукта. Так, применение поташа может быть использовано в сельском хозяйстве как в качестве самостоятельного эффективного бесхлорного удобрения, так и для получения комплексных калийно-фосфорных удобрений. Перспективным является применение белитового шлама для известкования кислых почв, которые составляют внушительную часть (около 25 \%) используемых земель страны. К другим сферам применения белитового шлама можно отнести производства стеновых блоков, силикатного кирпича, нефелин-керамзит-газобетонных панелей, легких, тяжелых и гидротехнических бетонов, асбоцементных и других изделий автоклавного твердения, приготовление строительных и штукатурных растворов, получение закладочных смесей, дорожное строительство [8].

По мнению автора, формирование рациональных направлений территориальной промышленной политики даст возможность активизировать процессы комплексной переработки сырья, что в дальнейшем даст новые импульсы развития как для предприятий и сфер города, так и всей социально-экономической системы.

В качестве возможного варианта решения проблем обеспечения минеральными ресурсами Ачинского глиноземного производства следует обратить внимание на «местное» сырье. Доказано, что месторождения алюминийсодержащих руд, находящиеся в Сибири, являются «пригодными» в качестве сырья для производства глинозема по технологии спекания руды с известняком с последующей гидрохимической переработкой спека. В настоящее время из более ста известных в Сибири месторождений алюминийсодержащих руд промышленно освоено только одно - Кия-Шалтырское, сырье, которое комплексно перерабатывается на Ачинском глиноземном комбинате с 1971 г. [9]. На сегодняшний день этот источник в значительной степени исчерпан, и за предприятием стоит выбор альтернативной его замены.

Исследования, проведенные автором ранее, дают возможность оценить целесообразность использования возможностей минерально-сырьевого комплекса на основе имеющихся решений, позволяющих осуществлять процесс производства глинозема. В качестве возможных вариантов сырьевого обеспечения были выбраны наиболее перспективные рудопроявления алюминийсодержащих пород: каолиновые глины Компановского месторождения, дистен-силиманитовые концентраты Базыбайского месторождения и бокситы Североонежской группы месторождений Иксинское, Плесецкое. Представленные варианты позволяют расширить круг сырья, которое может быть вовлечено в переработку [10].

Исследования ведущих ученых в области технологических решений алюминиевого производства выявили оптимальные соотношения компонентов различных видов алюминийсодержащего сырья. В таблице представлены варианты рудных смесей, исходя из процентного соотношения соответствующего сырья в рудной смеси.

Таблица. Составы минералов рудных смесей различных месторождений Table. Mineral compositions of ore mixtures from various deposits

\begin{tabular}{|c|c|c|c|c|c|c|c|c|c|}
\hline \multirow[b]{2}{*}{ Месторождение, сырье } & \multirow{2}{*}{$\begin{array}{c}\text { Состав } \\
\text { руд- } \\
\text { ных сме- } \\
\text { сей (в до- } \\
\text { лях) }\end{array}$} & \multirow[b]{2}{*}{$\begin{array}{l}\text { № } \\
\text { вари- } \\
\text { анта }\end{array}$} & \multicolumn{7}{|c|}{ Химический состав рудной смеси, \% } \\
\hline & & & $\mathbf{K}_{2} \mathbf{O}$ & MgO & $\mathrm{Fe}_{2} \mathrm{O}_{3}$ & $\mathrm{Al}_{2} \mathrm{O}_{3}$ & $\mathrm{CaO}$ & $\mathrm{SO}_{3}$ & $\mathrm{SiO}_{2}$ \\
\hline $\begin{array}{l}\text { Нефелиновая руда (Н) (Кия-Шал- } \\
\text { тырское) + Каолиновая глина } \\
\text { (Компановское) (Г) }\end{array}$ & $\begin{array}{c}0,7 H+ \\
0,3 \Gamma\end{array}$ & 1 & 2,552 & 1,060 & 3,578 & 28,24 & 5,920 & 0,210 & 43,19 \\
\hline $\begin{array}{l}\text { Нефелиновая руда (Н) (Кия-Шал- } \\
\text { тырское) + дистен-силиманито- } \\
\text { вые концентраты (ДСК) (Базы- } \\
\text { байское) }\end{array}$ & $\begin{array}{l}0,85 \mathrm{H}+ \\
0,15 \text { ДСК }\end{array}$ & 2 & 2,465 & 1,105 & 3,890 & 30,82 & 6,968 & 0,273 & 40,07 \\
\hline
\end{tabular}




\begin{tabular}{|c|c|c|c|c|c|c|c|c|c|}
\hline \multirow[b]{2}{*}{ Месторождение, сырье } & \multirow{2}{*}{$\begin{array}{c}\text { Состав } \\
\text { руд- } \\
\text { ных сме- } \\
\text { сей (в до- } \\
\text { лях) }\end{array}$} & \multirow[b]{2}{*}{$\begin{array}{l}\text { № } \\
\text { вари- } \\
\text { анта }\end{array}$} & \multicolumn{7}{|c|}{ Химический состав рудной смеси, \% } \\
\hline & & & $\mathbf{K}_{2} \mathbf{O}$ & MgO & $\mathrm{Fe}_{2} \mathrm{O}_{3}$ & $\mathrm{Al}_{2} \mathrm{O}_{3}$ & $\mathrm{CaO}$ & $\mathrm{SO}_{3}$ & $\mathrm{SiO}_{2}$ \\
\hline $\begin{array}{l}\text { Нефелиновая руда (Н) (Кия-Шал- } \\
\text { тырское) + Бокситы (Б) } \\
\text { (Иксинское, Плесецкое) }\end{array}$ & $\begin{array}{c}0,92 \mathrm{H}+ \\
0,08 \mathrm{~B}\end{array}$ & 3 & 2,734 & 1,235 & 4,600 & 28,58 & 7,500 & 0,327 & 38,31 \\
\hline $\begin{array}{l}\text { Нефелиновая руда (Н) (Кия-Шал- } \\
\text { тырское) - базовый вариант }\end{array}$ & $H$ & 4 & 2,090 & 1,300 & 4,400 & 26,50 & 8,100 & 0,300 & 40,1 \\
\hline
\end{tabular}

Проведенные автором исследования дали возможность оценить целесообразность использования возможностей минерально-сырьевого комплекса на основе имеющихся технологических решений.

Проведенные автором расчеты по взаимосвязанной системе эконометрических моделей глиноземного производства показали, что используемый в настоящее время вариант № 4 является самым высокозатратным, в то время как наименьшее значение себестоимости глинозема получено при использовании варианта № 2. Также необходимо отметить, что по мере исчерпания Кия-Шалтырского месторождения сокращается доля полезного компонента в составе используемой руды и с учетом возрастающей доли транспортных издержек в стоимости продукции, поэтому используемый в настоящее время на АГК вариант состава рудной смеси выглядит менее привлекательным.

Учитывая удельные расходы рудных смесей и их компонентов по каждому из вариантов, а также запасы различных месторождений, была оценена возможность продления времени эксплуатации используемого на сегодняшний день источника.

Стоит отметить, что данные по запасам руд месторождений алюминийсодержащего сырья имеют приблизительную оценку, которая основывается на сведениях тридцатилетней давности.

Оценка себестоимости глинозема и срока эксплуатации Кия-Шалтырского месторождения, а также срока эксплуатации месторождений различного алюминийсодержащего сырья, применяемого в качестве добавок, дает противоречивые результаты. Использования смеси нефелиновой руды Кия-Шалтырского месторождения Кия-Шалтырского месторождения и ДСК Базыбайского месторождения дают оптимальный результат с точки зрения себестоимости продукции. Оценивая возможности увеличения срока эксплуатации действующего месторождения нефелиновой руды в качестве приоритетного можно выделить первый вариант, однако запасы месторождения соответствующей добавки - каолиновой глины - оказываются недостаточными для реализации этого условия. Таким образом, задача выбора состоит в решении многокритериальной оптимизационной задачи, которая в качестве ограничений учитывает оценку вариантов использования минерального сырья различных месторождений. Решение этой задачи позволит обосновать перечень необходимых мер промышленной политики, которые позволят решить проблему сырьевого обеспечения алюминиевых производств.

Градообразующие предприятия определенным образом влияют на возможности развития моногородов, оказывая комплексное воздействие на функционирование производственной и социальной жизни общества. В этой связи проблемы отдельных предприятий должны рассматриваться как общие проблемы для развития всей территории, а их решение будет способствовать более эффективному развитию моногородов и регионов. Именно учет взаимосвязей при функционировании крупных производственных комплексов в системе национального производства должен стать основным ориентиром при формировании промышленной политики регионов России, разработке программ социально-экономического развития моногородов.

Результаты настоящего исследования целесообразно применять при планировании развития территории Красноярского края и, прежде всего, городов-металлургов. Учитывая истощение существующей сырьевой базы Ачинского глиноземного комбината, его роль и влияние на функционирование различных сфер и предприятий города, автор предлагает в качестве приоритетных мероприятий промышленной политики следующие:

- провести работы по определению запасов алюминийсодержащего сырья месторождений;

- разработать схему обеспечения сырьем глиноземного производства с учетом результатов выбора соответствующих месторождений с позиции наименьшей себестоимости продукции и увеличения сроков эксплуатации месторождений;

- разработать механизмы и инструменты государственного стимулирования производств, готовых активизировать процессы комплексной переработкой сырья;

- провести оценку экономических и социальных эффектов развития территории от предлагаемых мероприятий;

- разработать мероприятия по скорейшему освоению наиболее перспективных месторождений.

Реализация данных мероприятий позволит решить проблемы не только отдельного предприятия и отрасли, а также получить значительный социальный и экономический эффект на уровне города и региона. 


\title{
Литература
}

1. Курлеев М. О. К вопросу о проблемах функционирования и развития социально-производственного комплекса современного моногорода // Интеллект. Инновации. Инвестиции. 2011. № 4. С. 61-63.

2. Гундарев А. А. Моногорода Челябинской области: актуальные проблемы, потенциал и перспективы развития // Вестник Южно-Уральского государственного университета. Серия: строительство и архитектура. 2013. T. 13. № 1. C. $87-89$.

3. Наумов С. А. Проблемы устойчивого развития моногородов // Стратегия устойчивого развития регионов России. 2010. № 2. С. 218-222.

4. Черкасов В. В. Структурные изменения в современной российской промышленности // Экономические науки. 2011. № 84. С. 137-142.

5. Измайлова А. С, Бабич Е. И. Развитие регионов со старопромышленной металлургией на современном этапе // Актуальные проблемы современной науки, техники и образования. 2014. Т. 2. № 1. С. 215-218.

6. Другова Г. А., Тихонова М. В. Градообразующие предприятия в России: сущность, становление, перспектива // Вопросы экономики и права. 2017. № 105. С. 98-102.

7. Исаев А. Г. Территории опережающего развития: новый инструмент региональной экономической политики // ЭКО. Всероссийский экономический журнал. 2017. №4. С. 61-77.

8. Абрамов В. Я., Алексеев А. И., Бадальянц Х. А. Комплексная переработка нефелино-апатитового сырья. М.: Металлургия, 1990. $391 \mathrm{c.}$

9. Дашкевич Р. Я. Производство глинозема. Сырьевая база алюминиевой промышленности. Красноярск, 2003, $68 \mathrm{c}$.

10. Липин В. А., Баймаков А. Ю., Казаков В. Г. Пути совершенствования технологии переработки алюмосиликатного сырья на глинозем и сопутствующие продукты // Цветные металлы. 2014. № 4. С. 62-68.

\section{RATIONAL MANAGEMENT OF TOWN-FORMING INDUSTRIAL COMPLEXES AS AN INSTRUMENT FOR SUSTAINABLE DEVELOPMENT OF MONOTOWNS \\ TatianaA.Smirnoval,}

\author{
${ }^{1}$ Siberian Federal University, 79, Svobodny Ave., Krasnoyarsk, Russia, 660041 \\ @smirtatan@yandex.ru
}

Received 31.01.2018. Accepted 17.04.2018.

Keywords: economic and social development, raw material, alumina production, monotowns, integrated processing, industrial policy, cityforming enterprise.

\begin{abstract}
Town-forming enterprises determine the effectiveness of the functioning of certain territories and have a profound impact on the socio-economic situation of monotowns and their territorial development in general. In this regard, the problems of individual industries should be considered as general problems of the entire territorial system's development, as their solution will contribute to more effective development of monotowns and the region. The study has revealed the main problems in the main fields of aluminum production, i.e. alumina production. The author has conducted a full cycle of calculations for an interconnected system of econometric models of alumina production, which has allowed her to assess the possible options for raw material provision and propose actual solutions for the existing problems of the city-forming enterprises. To resolve one of the most acute matters, the author introduces a tool that will make it possible to achieve the optimal variant of material support, ensure the stable functioning of the enterprise and achieve sustainable development of the territory. The author also offers some measures of industrial policy that would solve the problems of one single enterprise and industry as well as create conditions for the stable development of the whole monotown.
\end{abstract}

For citation: Smirnova T. A. Reshenie problem gradoobrazuiushchikh predpriiatii kak perspektiva razvitiia monogorodov [Rational Management of Town-Forming Industrial Complexes as an Instrument for Sustainable Development of Monotowns]. Bulletin of Kemerovo State University. Series: Political, Sociological and Economic Sciences, no. 3 (2018): 162-167. DOI:10.21603/2500-3372-2018-3-162-167. 


\section{References}

1. Kurleev M. O. K voprosu o problemakh funktsionirovaniia i razvitiia sotsial'no-proizvodstvennogo kompleksa sovremennogo monogoroda [On the problem of the functioning and development of the social and industrial complex of a modern monotown]. Intellekt. Innovatsii. Investitsii = Intellect. Innovation. Investments, no. 4 (2011): 61-63.

2. Gundarev A. A. Monogoroda Cheliabinskoi oblasti: aktual'nye problemy, potentsial i perspektivy razvitiia [The monotowns of the Chelyabinsk region: actual problems, potential and development prospects]. Vestnik IuzhnoUral'skogo gosudarstvennogo universiteta. Seriia: stroitel'stvo $i$ arkhitektura $=$ Bulletin of the South Ural State University. Series: construction and architecture, 13, no. 1 (2013): 87-89.

3. Naumov S. A. Problemy ustoichivogo razvitiia monogorodov [Problems of sustainable development of singleindustry cities]. Strategiia ustoichivogo razvitiia regionov Rossii $=$ Strategy of sustainable development of Russian regions, no. 2 (2010): 218-222.

4. Cherkasov V. V. Strukturnye izmeneniia v sovremennoi rossiiskoi promyshlennosti [Structural changes in modern Russian industry]. Ekonomicheskie nauki = Economic sciences, no. 84 (2011): 137-142.

5. Izmailova A. S, Babich E. I. Razvitie regionov so staropromyshlennoi metallurgiei na sovremennom etape [Development of regions with old industrial metallurgy at the present stage]. Aktual'nye problemy sovremennoi nauki, tekhniki i obrazovaniia $=$ Current problems of modern science, technology and education, 2, no. 1 (2014): 215-218.

6. Drugova G. A., Tikhonova M. V. Gradoobrazuiushchie predpriiatiia v Rossii: sushchnost', stanovlenie, perspektiva [City-forming enterprises in Russia: essence, formation, perspective]. Voprosy ekonomiki i prava= Question of economy and right, no. 105 (2017): 98-102.

7. Isaev A. G. Territorii operezhaiushchego razvitiia: novyi instrument regional'noi ekonomicheskoi politiki [Territories of advanced development: a new instrument of regional economic policy]. EKO. Vserossiiskii ekonomicheskii zhurnal = Economy. All-Russian economic magazine, no. 4 (2017): 61-77.

8. Abramov V. Ia., Alekseev A. I., Badal'iants Kh. A. Kompleksnaia pererabotka nefelino-apatitovogo syr'ia [Integrated processing of nepheline-apatite rock]. Moscow: Metallurgiia, 1990, 391.

9. Dashkevich R. Ia. Proizvodstvo glinozema. Syr'evaia baza aliuminievoi promyshlennosti [Alumina production. Raw material base of the aluminum industry]. Krasnoyarsk, 2003, 68.

10. Lipin V. A., Baimakov A. Iu., Kazakov V. G. Puti sovershenstvovaniia tekhnologii pererabotki aliumosilikatnogo syr'ia na glinozem i soputstvuiushchie produkty [Ways to improve the processing technology of aluminosilicate raw materials for alumina and related products]. Tsvetnye metally = Magazine Non-ferrous metals, no. 4 (2014): 62-68. 